\title{
ESTADO, INDIVIDUO E IDENTIDAD
}

\section{STATE, IDIVIDUAL AND IDENTITY}

Fecha de recepción: 05-2-2017 Fecha de aceptación: 3-3-2017

\section{NÉSTOR NICOLÁS ARRÚA}

Licenciado en Historia de la Universidad Nacional de La Plata (UNLP) y Magíster en Trabajo Social (UNLP). Becario de investigación de la Secretaría de Ciencia y Técnica (SeCyT) de la UNLP. Actualmente se dedica a la investigación de la historia intelectual en el campo del Trabajo Social y los diálogos interdisciplinarios, específicamente, en el periodo de los años sesenta - setenta del siglo XX.

Resumen: El derrumbe del campo socialista y la reestructuración capitalista del trabajo consolidó la emergencia del neoliberalismo a escala mundial apoyado en la caída de los grandes relatos de la modernidad, que concebían sujetos de la historia hacia una meta de progreso cultural y económico. El neoliberalismo produjo reformas laborales y productivas que desencadenaron un redimensionamiento del mapa demográfico y económico mundial, con consecuencias de desplazamientos masivos de poblaciones ante la guerra y la penuria económica. Esto pone en jaque a los Estados nacionales que deben atravesar procesos de desterritorialización/territorialización de diversos sectores de su población, afectando las concepciones de ciudadanía y democracia dominantes en dichas sociedades.

El individuo deseado por las políticas e ideologías neoliberales como autosuficiente y dueño de sí mismo, repercute en la conformación de políticas dirigidas a atender la cuestión social, bajo una perspectiva ligada al empoderamiento y el emprendedorismo. Estas se encuentran atravesadas por procesos combinados de explotación del trabajo en las sociedades periféricas, que transforman las identidades colectivas y formas de protesta en la coyuntura actual. De esta manera, ante un individuo autoabastecido, conminado al consumo y el placer, la construcción de lo colectivo está a la orden del día.

Palabras claves: Neoliberalismo - individuo - identidad - Estado - Ideología.

\section{INTRODUCCIÓN}

Para abordar estos temas que requieren cada uno atención privilegiada será preciso tomar sus nexos económicos, políticos e ideológicos en la coyuntura actual con el objetivo de iluminar aspectos, lecturas, vislumbrar caminos futuros de trabajo. La propuesta es pensar históricamente estos temas a partir de distintas claves de análisis que preten-
Abstract: The collapse of the socialist camp and the capitalist restructuring of labor consolidated the emergence of neoliberalism on a world scale supported by the fall of the great accounts of modernity, which conceived subjects of history towards a goal of cultural and economic progress. Neoliberalism produced labor and productive reforms that triggered a resizing of the world demographic and economic map with consequences of mass displacements of populations in the face of war and economic hardship. This puts in check the national states that must undergo processes of deterritorialization / territorialization of diverse sectors of its population affecting the conceptions of citizenship and democracy dominant in these societies.

The individual desired by neoliberal policies and ideologies as self-sufficient and self-owner has repercussions in shaping policies aimed at addressing the social issue from a perspective linked to empowerment and entrepreneurship. These are traversed by combined processes of labor exploitation in peripheral societies that transform collective identities and forms of protest in the current conjuncture. In this way, before a self-supplied individual, conminado to consumption and pleasure, the construction of the collective is the order of the day. Key Words: Neoliberalism - Individual - Identity State - Ideology.

den trabajar sobre las configuraciones ideológicas, las transformaciones sociales y económicas, y los aparatos del Estado (1). Nos enfocamos en la indagación histórica y filosófica del individuo en tiempos del neoliberalismo en relación a la temática de las identidades, a partir de referenciales teóricos que nos permitan pensar la ideología (Louis Althusser) con miras de aportar algunas 
precisiones a la comprensión de los sujetos sociodeseantes. Nuestra intención es construir a partir de un dialogo interdisciplinar dirigido a grupos de trabajo y ateneos profesionales.

\section{PRIMER PUNTUALIZACIÓN: FIN DE LOS GRANDES RELATOS}

El corto siglo XX de Eric Hobsbawm estuvo signado por la Primera Guerra Mundial y la Revolución de Octubre hasta su implosión final en el año 1991. De esta forma, al quedar cerrada la experiencia soviética la revolución podía ser historizada, pensada en sus claroscuros.

La guerra y la revolución parecen demarcar temporalmente el siglo. La revolución proletaria en Rusia que inaugura una secuencia insurreccional en el mundo se transformó en una potencia imperial tras la Segunda Guerra Mundial hasta su desestructuración política e ideológica desde los años setenta hasta la hecatombe final en 1991.

La correlación de fuerzas en un mundo escindido, dividido en dos, como lo fue el siglo XX, permitió la aparición del Estado de Bienestar, una forma estatal que se presenta como pacto entre fracciones de clase que sostenían un alto nivel de empleo, seguridad social y una rentabilidad regulada. Las fuerzas políticas socialdemócratas dominaron la escena de los países centrales durante los años sesenta y setenta en oposición a las tendencias derechistas de partidos conservadores y a las fuerzas políticas radicalizadas de izquierda. La coyuntura histórica de los años setenta se caracterizó por la crisis del marxismo ante el accionar represivo de los países del "socialismo real", y la reestructuración económica en curso en los países centrales. Una verdadera "revolución" neoliberal produjo una transformación en las relaciones de producción y formas de explotación capitalista del trabajo más importante de los últimos tiempos y la emergencia de nuevas formas de estatalidad.

La caída del muro de Berlín en 1989, forma parte de un período victorioso para el llamado mundo occidental a partir del desprestigio en que recayó el socialismo, con las representaciones de la caída del comunismo (expuesta en la película Good bye, Lenin!) que terminaría por afectar al conjunto de las tendencias ideológicas de izquierda. La descomposición de la URSS y el afianzamiento de los gobiernos neoliberales en EE.UU. y Europa, consolidan las bases de una reforma de los sistemas de pensión y seguridad social con un fuerte aumento del desempleo.

La pasión por lo real que domina el siglo XX (2) cede ante el pensamiento único, el gerenciamiento social y la idea del 'fin de la historia', imposturas del triunfalismo neoliberal de los años noventa que buscaban mostrar un mundo ya no regido por ideologías sino por una idea de progreso de tipo nihilista -sin grandes objetivos u ideales-, gobernado por una democracia parlamentaria que impone la lógica consensual en el dominio indefinido del capital.

El fin de los grandes conflictos ideológicos y la paz durable en los países más desarrollados, parece haber sido ocluida en el año 2001 tras el atentado a las Torres Gemelas en EE.UU. La representación dominante actual en estos países es un estado de 'guerra permanente' contra el terrorismo que ha provocado intervenciones militares en países asiáticos y una construcción del enemigo interno identificado en comunidades migrantes consideradas "peligrosas". La intervención de los países de la OTAN en Medio Oriente no sólo se puede comprender como un capítulo más en el saqueo de los recursos petrolíferos y minerales de los países asiáticos por parte de Europa y EE.UU. sino que además trajo consecuencias indeseables para sus gobiernos: la entrada de centenares y miles de refugiados a la Unión Europea que pone en el tapete el tema de la xenofobia.

\section{SEGUNDA PUNTUALIZACIÓN: LA FORMA NACIÓN DEL ESTADO}

El Estado-Nación se erige en las postrimerías del siglo XIX mediante nuevos aparatos ideológicos y represivos que dieron forma y contenido a la idea de "nación". La escuela y el ejército nacional jugaron un destacado papel en la conformación de las identidades nacionales, modelando individuos en pos de ciudadanizar y civilizar la fuerza de trabajo. La necesidad de proletarizar la fuerza de trabajo, con el objetivo de crear las condiciones de su reproducción como mercancías para las necesidades de las relaciones de producción en el campo y la ciudad, se produjo mediante mecanismos jurídicos y represivos, al castigar el vagabundeo, el pillaje y al aplicar la ley de residencia en nuestro país para los inmigrantes que traían algo más que su fuerza de trabajo.

A la ola inmigratoria europea durante las postrimerías del siglo XIX y principios del siglo XX, se produce una masiva migración en los años treinta-cuarenta del campo a la ciudad producto de la crisis agrícola y la expansión de la producción industrial sustitutiva. De esta forma la constitución de una sociedad salarial centrada en el trabajo fabril conforma las identidades en la etapa fordista 
del capitalismo argentino en donde el peronismo modula las primeras manifestaciones del Estado de Bienestar en Argentina.

"Obreros/as", "trabajadores/as", "compañeros/ as" son los nombres de las identidades populares, constituidas a través del trabajo y el conflicto social, ciertamente en disputa con los sentidos patronales que tienden a denominar los mismos individuos: "mis empleados" o "mi personal". En los años cincuenta y sesenta en América Latina se producen movimientos migratorios muy importantes, ya mencionados, del campo a la ciudad que implica la circulación en las grandes urbes de identidades regionales y su identificación en el lugar periférico que ocupa en la ciudad: los "villeros".

Los sectores medios se mostraron reticentes a las identificaciones de los sectores populares al establecer una búsqueda de identidad propia a distancia de las clases dominantes. La clase media argentina se identifica como tal en relación a un estatus superior al "trabajador", como profesionales, comerciantes, técnicos, intelectuales, atravesada por tensiones ante su posición en la división del trabajo manual e intelectual y la necesidad de sostener su estatus social.

Las transformaciones del mundo del trabajo desde la última dictadura militar hasta el presente han ido en el camino de una desindustrialización selectiva, nuevas formas de explotación a través de los cambios en los marcos jurídicos que permiten una flexibilización de las formas de contratación y la tercerización de servicios a empresas con una expansión del cuentapropismo.

En nuestro país, las reformas neoliberales llevadas a cabo por el gobierno de Carlos Menem, mediante un partido popular en democracia que contó con una amplia hegemonía sobre diversos sectores sociales en la progresiva destrucción de los pilares del Estado de Bienestar, pero no sin resistencias por parte de trabajadores estatales, estudiantes y docentes que confluyeron en la Central de Trabajadores de Argentina (CTA).

El Estado-Nación se encuentra en tensión a causa de los efectos de las políticas neoliberales a partir de procesos de desterritorialización (3) de poblaciones que deben migrar a causa de guerras o por razones económicas. Importantes procesos migratorios afectan a ciertos países receptores que ponen en tensión los procesos de ciudadanización de los Estados nacionales, que presenta efectos combinados de discriminación racial y discriminación de clase que en nuestro país tiene una articulación específica.
Los procesos de desterritorialización que agitan a la soberanía nacional tiene un correlato extremo de territorialización, en la cual se producen dos fenómenos diferentes: por un lado, una porción de la burguesía argentina elije vivir separada del resto de la población en countries o barrios semicerrados, la soberanía es puesta en tela de juicio con el privilegio de la seguridad; por otro lado, una parte de los jóvenes y familias de los barrios más humildes de la periferia urbana compuesta por personas de diversas nacionalidades, migrantes por razones económicas, se encuentra fuertemente ligada a lazos locales (barriales) atravesada por situaciones problemáticas con anuencia de distintos actores del Estado.

En los países de América Latina, distintos levantamientos populares y la crisis del consenso de los gobiernos neoliberales de los años noventa tuvo como consecuencia la emergencia de gobiernos de izquierda y centro izquierda. Los avances en sus políticas redistributivas hacia los segmentos más empobrecidos en conjunción con nuevos derechos civiles y políticos se vieron sopesados con la permanencia de las lógicas de acumulación neoliberal. Estas ambivalencias de los gobiernos llamados "populistas" fue uno de los elementos que abonaron el terreno para la formación de fuerzas conservadoras, en un tono renovado, ante el continuo conflicto social que se presenta en estas sociedades.

\section{TERCERA PUNTUALIZACIÓN: NEOLIBERA-} LISMO, INDIVIDUO E IDENTIDAD

La idea neoliberal del individuo como dueño o propietario exclusivo de su cuerpo y de lo que produce, un ser autoabastecido que se esfuerza por conquistar su propiedad y defenderla a pesar del Estado, se entronca con los cambios socioeconómicos en los procesos de trabajo en una secuencia histórica de los años setenta-ochenta. Se trata de que el Estado regule a favor de la creación de mercados y promueva la mercantilización de bienes culturales, naturales, económicos, y provea de seguridad para el desarrollo de los negocios. El objetivo es culminar con las formas de dependencia del individuo respecto del Estado expresado en términos negativos en el crecimiento del empleo público o planes asistenciales, y alienta formas de abordar la cuestión social a partir de las políticas de empoderamiento (empowerment) que busca reforzar la aspectos psicológicos del individuo - la autoestima-, en la ruptura de lazos de dependencia, o el emprendedorismo, con la intención de que el individuo se convierta en empresario de sí 
mismo. En todos los casos, reclama un individuo amo de sí mismo ante lo cual Freud tendría serias objeciones.

La idea del homo economicus aparece vinculado a una noción darwinista social de 'lucha por la vida', en donde los que mejor se adaptan y evolucionan sobreviven en un mundo de competencia desenfrenada. Sin embargo, las grandes empresas capitalistas han gozado, y continúan, de los contratos y protección regulatoria del Estado, por lo cual, esta noción sólo es válida para una porción (mayoritaria) de la población.

Tenemos que cuestionar la idea de una clase obrera unificada y homogénea, aunque cabe preguntarse si ésta alguna vez lo fue. Las representaciones de la clase, como bloques enfrentados, obedece a la necesidad del Estado de Bienestar de identidades estables en pos de sellar un pacto de productividad, salario y paz social. Éste requería un interlocutor entre los actores de la economía para la búsqueda del bienestar. El Estado neoliberal no busca la interlocución con colectivos sociales y políticos, sino que desea la dispersión organizativa porque no está dispuesta a la idea de un pacto social.

Las modernas reformas de los regímenes de contratación a través de una flexibilización de los tiempos y polivalencia de tareas con la consecuente pérdida de derechos laborales y seguridad social (informalización), o con una forma de tercerización transforma la fisonomía del mundo laboral. Las nuevas formas de explotación del trabajo (o "sobretrabajo") se articulan con otras ya existentes en nuestra formación social: la explotación del trabajo agrícola en extensas jornadas sin contrato de trabajo, trabajo no remunerado de niños, formas de servidumbre en talleres textiles clandestinos, trabajo a destajo en formas de autoexplotación.

La tecnología de comunicación en la actualidad juega un rol destacado en la explotación del trabajo, específicamente, en la permanente disponibilidad del trabajador y el uso de tiempos de ocio para el trabajo, con la consiguiente accesibilidad de información para el desarrollo de diversas tareas simultáneas. De esta manera, se aumenta la productividad mediante el aceleramiento de los tiempos de trabajo propiciado por facilidades de realización de tareas en colaboración o red. La principal consecuencia de este avance técnico en la comunicación e informatización de las relaciones sociales vuelve a presentar al individuo como un "dios con prótesis" (Freud), que mediante la escritura busca exorcizar la ausencia cuando sólo la invoca constantemente.

El individuo ya no debe obediencia a una autoridad tradicional, hoy en día vilipendiada, sino a formas de placer que ofrece el mercado de entretenimiento (4), el cual porta un mandato de felicidad. "Debes ser feliz" es el precepto que rige en lo sexual con un repertorio de goces y perversiones pasibles de ser consumidos con una búsqueda de superar la instantaneidad mediante nuevas formas cada vez más breves de placer. El cuerpo del placer se refuerza con la explotación del mismo al ser portador de energía -renovable-, que alimenta las fantasías futuristas de Hollywood, desde Matrix a Black Mirror.

Alcanzar el objetivo de felicidad individual determina por lo menos dos formas de relacionarnos con otros, el primero caracterizado por el individuo-rey, egoísta, autosuficiente, que concibe sólo relaciones utilitaristas con otras personas, o también las caracterizadas por el altruismo, que actúa sobre prácticas caritativas, voluntaristas (5).

El individualismo, en las sociedades actuales, se presenta regido por una supremacía imaginaria del individuo que lo erige como el único "culpable" de las anormalidades y disfuncionamientos colectivos y personales, lo que supone situar la mirada exclusivamente en ese lugar que afianza un psicologismo (6). Lo colectivo asume un lugar de "crisis" ante la égida del individualismo, sin embargo, la consideración de lo colectivo resulta fundamental para comprender las modalidades de transitar de los sujetos en las instituciones o grupos. La construcción de los colectivos requiere de un trabajo cotidiano, democrático, sin caer en representaciones idílicas, en tanto uniformes e indivisos, estos no están exentos de tensiones y luchas.

\section{PARA CONCLUIR...}

Las identidades de la clase obrera se han formado por el encuentro histórico de fracciones de clase del campo y la ciudad con agrupamientos intelectuales, siempre en conflicto y destinadas a cambiar porque el capitalismo continúa su reproducción de manera incesante. El Estado siempre está mediando en la formación de las clases a través de discursos y marcos jurídicos, en la cual una lucha ideológica se desarrolla en cada una, podríamos decir: hay lucha de clases dentro de cada clase (7). El Estado en su forma nacional se encuentra en tensión por diversos procesos convergentes que modulan las formas de individuación, las estructuras de las familias, los géneros, la salud pública, etc. 
Las identidades poseen dos almas contradictoras: el alma Parménides, que se caracteriza por una invariante que localizamos en los nombres, en los calificativos reproducidos por el Estado (hombre, mujer, empleado, desempleado, etc.) en una operación de desmultiplicación y limitación de las posibilidades que son utilizados en la cuenta como uno (Badiou, 2010: 23); el alma Heráclito, que representa a las identidades como ineludiblemente temporales, hijas del conflicto y las circunstancias.

La identidad individual está asociada a identificaciones en un campo de valores y símbolos colectivos, en donde el sujeto es el soporte de configuraciones ideológicas que adoptan formas conscientes e inconscientes (3). La presentación conflictiva de la política y las demandas sociales, civiles y políticas coloca constantemente la cuestión de las identidades frente al Estado, que este desconoce o pretende a un interlocutor reconocible, solvente.

\section{NOTAS}

(1) Este trabajo forma parte de un conjunto de reflexiones personales promovidas por la participación en el Seminario Diurno de la Escuela de Orientación Lacaniana, Sección - La Plata (2016), titulado: "Comedia de la identidad, insistencia de lo real” de la Lic. Gabriela Rodríguez y la Lic. Cecilia Fasano.

(2) Badiou, A.: El siglo. Buenos Aires, Manantial, 2005, p. 83.

(3) Balibar, E.: "Los dilemas históricos de la democracia y su relevancia contemporánea para la ciudadanía", en Enrahonar. Quaderns de Filosofia, Barcelona, n 48, 2012, p. 21.

(4) Žižek, S.: "You may!”, London Review of Books, vol. 21, n 6, 1999.

(5) Realizamos una apropiación personal de las precisiones efectuadas por Sigmund Freud en el Malestar en la cultura, p. 3064.

(6) Karsz, S.: “¿Supremacía del individuo y crisis del colectivo?”, en revista Los Trabajos y los Días, FTS-UNLP, n 4/5, 2014, p. 86.

(7) Balibar, E.; Wallerstein, I.: Raza, nación y clase. Madrid, Iepala, 1988, p. 265.

(8) "De ahí el asombro absolutamente sincero que sentimos al descubrirnos portadores de valores que, con la misma sinceridad, decíamos detestar", en Karsz, S. Problematizar el trabajo social. Definición, figuras, clínica. Barcelona, Gedisa, 2007, p. 84. Según Saül Karsz, la ideología y el inconsciente están anudados, son dos lógicas que se encuentran ya imbricadas.

\section{BIBLIOGRAFÍA}

- Althusser, L. "Ideología y Aparatos Ideológicos del Estado”, en Žižek, S. (comp.) Ideología. Un mapa de la cuestión. Buenos Aires, FCE, 2003.

- Badiou, A.: El siglo. Buenos Aires, Manantial, 2005.

- Badiou, A.: "La idea del comunismo", en Hounie, A. (comp.) Sobre la idea de comunismo. Buenos Aires, Paidós, 2010.

- Balibar, E.; Wallerstein, I. Raza, nación y clase. Madrid, Iepala: 1988.

- Balibar, E.: "Los dilemas históricos de la democracia y su relevancia contemporánea para la ciudadanía”, en Enrahonar. Quaderns de Filosofia, Barcelona, n $48,2012$.

- Hobsbawm, E.: Historia del siglo XX. Buenos Aires, Crítica, 1998.

- Freud, S.: El malestar en la cultura, en Freud, S. Obras Completas. Buenos Aires, Siglo XXI, 2012

- Freud, S.: Psicología de las masas y análisis del yo, en Freud, S. Obras Completas. Buenos Aires, Siglo XXI, 2012.

- Karsz, S.: “'Supremacía del individuo y crisis del colectivo?”, en revista Los Trabajos y los Días, FTS-UNLP, nº 4/5, 2014.

- Karsz, S.: Problematizar el trabajo social. Definición, figuras, clínica. Barcelona, Gedisa, 2007

- Lacan, J.: "El estadio del espejo como formador de la función del yo (je) tal como se nos revela en la experiencia analítica”, en Žižek, S. (comp.) Ideología. Un mapa de la cuestión. Buenos Aires, FCE, 2003.

- Morresi, S.: La nueva derecha argentina. Polvorines, UNGS, 2008.

- Žižek, S.: “You may!”, London Review of Books, vol. 21, nº 6, 1999. 